\title{
LA TEORÍA DE LOS ACTOS PROPIOS Y SU APLICACIÓN EN LA LEGISLACIÓN PERUANA
}

\author{
César Aníbal Fernández Fernández ${ }^{1}$
}

\section{RESUMEN}

La Teoría de los Actos Propios precisa que "a nadie le es lícito hacer valer un derecho en contradicción con su anterior conducta, interpretada objetivamente según la ley, las buenas costumbres, la buena fe, justifica la conclusión de que no se hará valer el derecho, o cuando el ejercicio posterior choque contra la ley, las buenas costumbres o la buena fe

Constituye pues, una regla de derecho que se deriva del principio de la buena fe, el cual sanciona como inadmisible toda pretensión lícita pero objetivamente contradictoria con respecto al propio comportamiento anterior efectuado por la misma persona.

Esta doctrina se halla vinculada directamente con los principios generales del derecho y en particular con el de buena fe, pero también ha sido enfocada como medio de defensa contra el accionar incoherente y también como una nueva forma de restricción o limitación en el ejercicio de derechos

Esta teoría busca fomentar que las personas sean coherentes en su actuar cotidiano. De esta manera, sanciona a las personas que se comportan contradictoriamente quitándoles la posibilidad de reclamar derechos que en un primer momento sí hubieran podido reclamar.

El fundamento de esta teoría es que la mayoría de personas actúan confiando en los demás. Por lo tanto, si alguien actúa de tal manera que su conducta aparenta que no reclamará un derecho, no puede luego hacer valer ese derecho contra quien confió en tal apariencia. Se trata pues de una norma de buena conducta, basada en la buena fe de las partes.

Así, si una persona desarrolla un comportamiento del que se puede derivar confianza en un hecho, y luego desarrolla una conducta que es contraria a la que realizó antes, entonces será de aplicación esta teoría.

\section{PALABRAS CLAVE}

Actos Propios; ley; buenas costumbres; buena fe; derecho.

\section{ABSTRAC}

The Theory of Acts states that "no one is entitled to assert a right in contradiction with his previous conduct, interpreted objectively according to law, good customs, good faith, justifies the conclusion that the right will not be enforced, or when the subsequent exercise conflicts with the law, good customs or good faith

It is therefore a rule of law that derives from the principle of good faith, which sanctions as inadmissible any claim licit but objectively contradictory with respect to the previous behavior carried out by the same person.

1 DOCTOR EN DERECHO, PhD Graduate DOCTOR OF PHILOSOPHY IN BUSINESS ADMINISTRATION por la Atlantic International University of Miami-Florida, Estados Unidos de Norteamerica; MAGÍSTER EN DERECHO CIVIL; MAESTRÍA EN DERECHO DE LA EMPRESA por la Pontificia Universidad Católica del Perú; MAESTRIA EN COMERCIO INTERNACIONAL por la Escuela de Negocios de Posgrado de la Universidad San Pablo CEU- Madrid- España, en convenio con el Instituto Europeo de Posgrado de Madrid-España); Diplomado del Primer Programa para la Acreditación de Docentes PAD-AMAG de la Academia de la Magistratura en convenio con la Universidad de Alicante- España en "LA ENSEÑANZA DEL DERECHO Y ARGUMENTACIÓN JURÍDICA". Diplomado en "FORMACIÓN DE DOCENTES POR COMPETENCIAS", dictado por la Universidad ESAN en convenio con la Academia de la Magistratura. Catedrático Universitario en Derecho Civil y Derecho Empresarial. Docente Asociado UNIFE. 
This doctrine is directly linked to the general principles of law and in particular to the principle of good faith, but it has also been focused as a means of defense against incoherent action and also as a new form of restriction or limitation in the exercise of rights

This theory seeks to encourage people to be consistent in their daily actions. In this way, it sanctions the people who behave contradictorily removing the possibility of claiming rights that at first could have been claimed.

The foundation of this theory is that most people act by trusting others. Therefore, if someone acts in such a way that his behavior appears that he will not claim a right, he can not then assert that right against whom he trusted in that appearance. It is therefore a rule of good conduct, based on the good faith of the parties.

Thus, if a person develops a behavior from which one can derive confidence in a fact, and then develops a behavior that is contrary to that which he performed before, then this theory will apply.

\section{Key Words:}

Own Acts; law; good manners; good faith; law.

\section{ANTECEDENTES:}

La denominada Teoría de los Actos Propios tiene sus antecedentes en el Derecho Romano, el cual se limitó a hacer una cierta aplicación de la citada teoría en algunos casos concretos. Aunque no se formuló una definición específica de esta teoría, es en el Derecho Romano donde se comienza a sancionar como inadmisible la actuación contraria a la conducta anterior, pero ello no de una manera general sino en determinados casos y con algunas excepciones.

Dicha inadmisibilidad dio origen, entre otros, a los brocardos: venire contra factum proprium nulli conceditur y adversus factumsuum quis venire non protest. Dichos brocardos, aunque son latinos, no han nacido en el Derecho Romano, sino en el Derecho Intermedio, aquel periodo comprendido desde el redescrubrimiento del Corpus luris Civiles, en el siglo $\mathrm{XI}$, hasta el momento de las codificaciones, etapa poco conocida y a la vez importante porque en ella nacen la mayo- ría de nuestros dogmas, y comprende a los glosadores, posglosadores, canonistas, prácticos y tratadistas.

La formulación más antigua que se conoce de la regla que prohíbe venir contra los Actos Propios es un pasaje de Ulpiano que recoge el fragmento 25 del Digesto 1,7, en él se afirma que resulta inadmisible que el padre pretenda iniciar, una vez muerta la hija que ha vivido como mater familias emancipada y que ha instituido herederos por testamento, una controversia alegando que la emancipación no ha sido jurídicamente eficaz. Sin embargo, esta actitud es inadmisible debido a que él mismo ha permitido que su hija sea tratada como sui iuris, es decir, le ha permitido vivir como si fuera emancipada aún cuando no hubieran sido cumplidos los requisitos establecidos en el Derecho Romano. Por ello se resolvió que el padre que ha consentido que la hija sea tratada como sui iuris no puede ignorar o desconocer tal estado y, por lo tanto, no puede pretende impugnar el testa- mento. Es necesario destacar que la solución dada en el referido caso, como lo sostiene Diez-Picazo no tiene como primera razón sancionar la conducta contradictoria sino, más bien, evitar un resultado que objetivamente es considerado injusto

La Teoría de los Actos Propios, tal como la definen Marcelo J. López Mesa y Carlos Rogel Vide, consiste en una limitación al ejercicio de un derecho, que reconoce como fundamento una razón de política jurídica: la protección de la confianza suscitada por el comportamiento antecedente, que luego se pretende desconocer.

Como señalan los referidos autores, la Teoría de los Actos Propios constituye una derivación inmediata y directa del principio de la buena fe, reconocido por la jurisprudencia argentina en una infinidad de pronunciamientos, especificándose en algunas sentencias, que se trata de un principio que integra el Derecho positivo. 
El profesor Fueyo Laneri define a la Teoría de los Actos Propios como un principio general de derecho, fundado en la buena fe, que impone un deber jurídico de respeto y sometimiento a una situación jurídica creada anteriormente por la conducta de la misma persona, evitando así la afectación a un interés ajeno y el daño consiguiente, la teoría obliga a una conducta leal, honesta, confiable y que encuentra apoyo natural en la moral.

En conclusión, como lo señala Alejandro Borda, la teoría de los Actos Propios constituye una regla de derecho que se deriva del principio de la buena fe, el cual sanciona como inadmisible toda pretensión lícita pero objetivamente contradictoria con respecto al propio comportamiento anterior efectuado por la misma persona.

Esta doctrina se halla vinculada directamente con los principios generales del derecho y en particular con el de buena fe, pero también ha sido enfocada como medio de defensa contra el accionar incoherente y también como una nueva forma de restricción o limitación en el ejercicio de derechos

\section{a) ¿En que consiste la teoría de los Actos Propios?}

La denominada teoría de los Actos Propios nace del latín "venire contra factum propium nulli conceditur", de allí la expresión "venir contra" sus actos supone la autocontradicción del individuo con un obrar anterior.

La frase "venire contra factum proprium nulli conceditur" es una regla orientada a impedir "una falta de probidad (improbitas) y un resultado objetivamente injusto, que consiste en la pretensión de una persona de alterar su propia posición y contradecirse consigo misma en perjuicio de otra".

La teoría de los actos propios "Es en el lenguaje usual del Derecho, la responsabilidad de todas las consecuencias jurídicas, es decir, cada uno es responsable de sus propios actos y de los efectos que estos se producen, salvo excepciones legales"'.

Consiste en una norma de justicia general la cual precisa que "a nadie le es lícito hacer valer un derecho en contradicción con su anterior conducta, interpretada objetivamente según la ley, las buenas costumbres, la buena fe, justifica la conclusión de que no se hará valer el derecho, o cuando el ejercicio posterior choque contra la ley, las buenas costumbres o la buena fe"3

El principio de los actos propios es consecuencia de la buena fe, pues significa que no es válido ir contra los propios actos cuando éstos reúnen los requisitos y presupuestos previstos en la ley y con ellos se determina una situación jurídica.

Según Fraga: “Aún cuando es cierto que a la facultad positiva de crear un acto debiera corresponder la facultad contraria de destruirlo, también es cierto que el ejercicio de esa facultad negativa puede ser regulado en forma distinta del ejercicio de la facultad positiva, ya que una vez que el acto se ha producido entra en la vida del derecho como una entidad autónoma e independiente, produciendo efectos de los cuales ya no puede disponer en forma ilimitada su autor". ${ }^{4}$

Diez Picazo, habla de casos en el que aunque el derecho no puede considerarse como prescrito, su ejercicio ha sido demorado en forma tal que resulta contrario a la buena fe el posterior intento de hacerlo valer, por lo que concluye que la vulneración de dicha doctrina se produce a virtud del prolongado retraso en el ejercicio del derecho, objetivamente desleal, que suponen una tácita renuncia y una inequívoca aquiescencia dada la situación del demandado. ${ }^{5}$

Esta teoría busca fomentar que las personas sean coherentes en su actuar cotidiano. De esta manera, sanciona a las personas que se comportan contradictoriamente quitándoles la posibilidad de reclamar derechos que en un primer momento sí hubieran podido reclamar.

Diccionario Jurídico OMEBA, Tomo I, Editorial Driskill S.A., Buenos Aires, 1976, pág. 440

Enneccerus, Ludwig y Nipperdey, Hans. Tratado de Derecho Civil. Parte General. Barcelona, Bosch, Tomo I, Volumen 2, 1950, p.495;.

4 Fraga, Gabino, Derecho administrativo, 33a. ed. rev. y act. por Manuel Fraga, México, Porrúa, 1994. nota 6, pp. 305 y 306

5 Diez Picazo, Luis. Dictámenes Jurídicos. Editorial Civitas. Madrid 1981., p. 208. 
El fundamento de esta teoría es que la mayoría de personas actúan confiando en los demás. Por lo tanto, si alguien actúa de tal manera que su conducta aparenta que no reclamará un derecho, no puede luego hacer valer ese derecho contra quien confió en tal apariencia. Se trata pues de una norma de buena conducta, basada en la buena fe de las partes.

Así, si una persona desarrolla un comportamiento del que se puede derivar confianza en un hecho, y luego desarrolla una conducta que es contraria a la que realizó antes, entonces será de aplicación esta teoría.

DIEZ PICAZO precisa que: “Una de las consecuencias del deber de obrar de buena fe y de la necesidad de ejercitar los derechos de buena fe, es la exigencia de un comportamiento coherente. La exigencia de un comportamiento coherente significa que, cuando una persona, dentro de una relación jurídica, ha suscitado en otra con su conducta una confianza fundada, conforme a la buena fe, en una determinada conducta futura, según el sentido objetivamente deducido de la conducta anterior, no debe defraudar la confianza suscitada y es inadmisible toda actuación incompatible con ella. La exigencia jurídica del comportamiento coherente está de esta manera estrechamente vinculada a la buena fe y a la protección de la confianza"

Asimismo, BORDA refiere que: "es necesario proteger la creencia y confianza que se despierta en un sujeto por el comportamiento de otro, confianza y creencia éstas que nacen de la exigencia de mantener un comportamiento coherente; este es, mantener una conducta honesta, recta, honrada y proba

\section{b) Presupuestos o Requisi- tos para la aplicación de la Doctrina de Los Actos Pro- pios}

Los elementos configurativos, o sea, las condiciones fundamentales para la aplicación de la doctrina de los actos propios, podemos sintetizarla de la siguiente manera:

1) Una situación jurídica preexistente.

2) Una conducta del sujeto, jurídicamente relevante y plenamente eficaz, que suscite en la otra parte una expectativa seria de comportamiento futuro.

3) Una pretensión contradictoria con esa conducta atribuible al mismo sujeto.

Esto significa que para que se configure esta doctrina es necesario que exista una conducta previa y una pretensión posterior emanadas de la misma persona y que se hayan producido ambas frente a la misma contraparte y dentro del marco de la misma relación o situación jurídica.

Es decir, que existan identidad de partes y unidad de situación jurídica, que esta conducta previa sea válida y que revista sentido unívoco y cierta entidad de modo de poder ser interpretada como una voluntaria toma de posición de su autor respecto de las circunstancias de una relación o situación jurídica y que tal conducta (o su consecuencia necesaria) y tal pretensión sean contradictorias, o sea incompatibles entre sí; pero aunado a estos requisitos se deberá tomar en cuenta también que dentro del ordenamiento jurídico no haya norma que autorice la contradicción.

Así pues: " La teoría de los actos propios requiere para poder ser aplicada la existencia de una conducta anterior relevante y eficaz; es decir, se necesita una primera conducta, también llamada vinculante" 6

Al referirnos de conducta jurídica relevante se debe considerar solo a aquella que opera trascendentalmente en el mundo del derecho y que particularmente afecte o incida en la relación jurídica establecida por las partes, debiendo por tanto, excluirse las conductas ajenas a dicha relación jurídica.

Asimismo como requisito para la aplicación de esta Doctrina se requiere una pretensión contradictoria, esto es que existen dos conductas, caracterizándose la primera por la confianza que ofrece a los demás y una segunda que atente precisamente contra ésta confianza obtenida.

A su vez debe existir identidad de sujetos que se vinculan en ambas conductas. "Sujeto ac-

6 Borda, Alejandro, Op. Cit. Pág. 72 
tivo es la persona que ha observado determinada conducta y debe ser el mismo que pretende luego contradecir esa primera conducta.... sujeto pasivo es la persona que ha sido receptor o destinatario de ambas conductas"

Como acertadamente precisa Borda, si bien es cierto, esta regla no está configurada normativamente, es innegable su utilización en el campo del derecho procesal sobretodo.

Así pues, señala el mencionado autor $^{8}$ esta doctrina para su aplicación requiere, que el sujeto pasivo demuestre que, en relación con el mismo, el sujeto activo del derecho subjetivo haya desplegado con anterioridad una conducta que, interpretada de buena fe, demuestra la contradicción o incompatibilidad de la nueva postura del titular del derecho subjetivo, circunstancia que, en definitiva, destruye la confianza que para el sujeto pasivo comportaba la conducta anterior del sujeto activo. Por tanto, dicha ruptura de la confianza ha de considerarse contraria a la buena fe, en cuanto al titular del derecho subjetivo no puede actuar a su antojo y por mero capricho, jugando con las expectativas de las personas que con él se relacionan.

\section{c) ¿Se aplica la Doctrina de los Actos Propios en nues- tra legislación?}

Por supuesto que sí. Existen diversos artículos contemplados en el Código Civil que se

Borda, Alejandro, Op. Cit. Pág. 82

8 Borda, Alejandro, Op. Cit. Pág. 83 encuentran inspirados en la acotada Doctrina de los Actos Propios.

Inclusive, debemos recalcar que la referida doctrina ha sido aplicada por la jurisprudencia, al amparo de nuestra normatividad vigente. Consideramos que no se trata de una aplicación jurisprudencial al amparo de principios jurídicos no reconocidos por nuestro ordenamiento, ni tampoco se puede equivocadamente sostener que se trata de una aplicación de la norma por analogía. Todo lo contrario, se trata de la aplicación de normas vigentes en nuestra propia legislación.

Citamos algunos ejemplos: Los artículos 168 y 1362 del Código Civil.

El primero de los nombrados se refiere a la interpretación objetiva del Acto Jurídico, al estipular: "El acto jurídico debe ser interpretado de acuerdo con lo que se haya expresado en él y según el principio de la buena fe"

El segundo se refiere a la buena fe y común intención de las partes en los contratos, estableciendo: "Los contratos deben negociarse, celebrarse y ejecutarse según las reglas de la buena fe y común intención de las partes"

Sin duda, lo común que tienen los artículos citados y por ende es de relevancia para la Teoría de los Actos Propios, es que en ambos casos se refieren al principio de la buena fe y que los actos o conductas de las partes posteriores a la celebración del acto jurídico o del contrato no deben ser contradictorias entre ellas mismas, caso contrario, se estaría lesionando el principio de la buena fe y consecuentemente, se configurarían los elementos necesarios para que se de la figura jurídica de la Doctrina de los Actos Propios.

De otro lado, existen otros casos contemplados en el mismo Código Civil, como por ejemplo el Art. 226 que establece que: "La incapacidad de una de las partes no puede ser invocada por la otra, en su propio beneficio, salvo cuando es indivisible, el objeto del derecho de la Obligación".

Así mismo el Art. 231 del mismo cuerpo legal señala: "El acto queda también conformado si la parte a quien correspondía la acción de anulación conociendo la causal, lo hubiese ejecutado en forma parcial o total, si existe hechos inequivocablemente que pongan en manifiesta la intención de renunciar a la acción de anulabilidad.

En cuanto al Código Procesal Civil, tenemos el Art. 172 que estipula que tratándose de vicios en la notificación de la Nulidad existe convalidación tácita cuando el facultado para plantear la nulidad no formula su pedido en la primera oportunidad que tuviera para hacerlo

Así mismo, el Art. 388 del citado Código Procesal hace 
referencia a los requisitos de fondo del recurso de apelación en cuanto que el recurrente no hubiera consentido previamente la resolución adversa de primera instancia.

De otro lado, en la Ley General de Arbitraje Ley $N^{\circ} 26572$ en su Art. 15, el cual señala que "Las partes pueden renunciar al Arbitraje mediante convenio expreso. Se entiende que existe renuncia tácita cuando se hubiera interpuesto demanda por una de las partes y el demandado no invoca la excepción arbitral dentro de los plazos previstos para cada proceso".

Del mismo modo, en la Ley General de Sociedades en su artículo 48 indica que "No procede interponer las acciones judiciales contempladas en esta ley o en las de aplicación supletoria a ésta cuando exista convenio arbitral obligatorio contenido en el pacto social o en el estatuto que someta a esta jurisdicción resolver discrepancias que se susciten...".

\section{d) Fundamentos de la Doctri- na de los Actos Propios}

El fundamento de este principio se encuentra claramente explicado por Morello ${ }^{9}$, quien señala “ Estará dado en razón que la conducta anterior ha generado -según el sentido objetivo que de ella se desprende confianza en que, quien la ha emitido, permanecerá en ella, pues lo contrario importaría incompatibilidad o con- tradicción de conductas emanadas de un mismo sujeto, que afectan injustamente la esfera de intereses de quien suponía hallarse protegido pues había depositado su confianza en lo que creía un comportamiento agotado en su dirección de origen."

Dentro de este contexto, si frente a determinados acuerdos una parte se comporta respecto de ellos con tolerancia, buena fe y respetando sus alcances, entonces quien lleva a cabo tales acuerdos puede confiar que en el futuro no serán cuestionados, ni mucho menos contradecirlos.

Sin duda, ello es aún más claro si se tiene en consideración que no existe razón ni fundamento legal alguno para poder posteriormente cuestionarlos.

En dicho aspecto, diversos autores se han pronunciado fijando claramente la misma posición.

De esta manera, Diez Picazo ${ }^{10}$ precisa: "Hemos llegado a la conclusión de que la regla, que normalmente se expresa diciendo que nadie puede venir contra sus propios actos, ha de interpretarse en el sentido de que toda pretensión, formulada dentro de una situación litigiosa por una persona que anteriormente ha realizado una conducta incompatible con esa pretensión, debe ser desestimada. Hemos llegado también a la conclusión de que, desde un punto de vista de derecho sustantivo, la inadmisibilidad de venir contra los Actos Propios constituye técnicamente un límite del ejercicio de un derecho subjetivo o de una facultad, derivado del principio de la buena fe y particularmente, de la exigencia de observar, dentro del tráfico jurídico, un comportamiento coherente."

Betti $^{11}$, es de la misma opinión, al señalar: "La buena fe, hemos dicho varias veces, implica un deber de coherencia del comportamiento que consiste en la necesidad de observar en el futuro la conducta que los actos anteriores hacían prever".

Lehmann $^{12}$ confirmando el mismo principio agrega: "La necesidad de coherencia del comportamiento limita los derechos subjetivos y las facultades del sujeto, que sólo pueden ser ejercitadas en la medida en que este ejercicio sea coherente o compatible, no contradictorio, con el comportamiento anterior".

Por su parte, Alsina Atienza, citado por Borda ${ }^{13}$ considera que la Doctrina de los Actos Propios: "Se reduce a que, quien, mediante cierta conducta, positiva o negativa, infunde o crea en otra persona, la confianza fundada de que aquel mantendrá su comportamiento en lo sucesivo, deberá, sí, mantenerlo efectivamente, aunque en su fuero interno hubiere abrigado otro propósito en realidad".

\footnotetext{
Morello, Augusto “Dinámica del Contrato. Enfoques” Librería Editorial Platense. 1985. p. 59.

Diez Picazo, Luis. “La Doctrina de los Actos Propios” p. 193.

Citado por Diez Picazo, op cit, p. 245.

Citado por Diez Picazo, op cit, p. 245.

Borda, Teoría de los Actos Propios, Abeledo Perrot, Buenos Aires, p. 41.
} 
Dentro de la Doctrina nacional, tenemos a René Ortiz ${ }^{14}$ quien precisa: "Lo inicuo de contradecir un acto propio estribaba en el perjuicio que se ocasionaría al que se sustentó en, o benefició con, el acto objeto de impugnación, quien se condujo creyendo en la validez del acto en mención $y$, o, confiando en la rectitud de conducta del ahora impugnante".

Riezler, citada por $\mathrm{Borda}^{15}$, quien al hacer una enumeración de hipótesis a las que resultaría aplicable la "verwirking" , posición alemana en relación a la Teoría de los Actos Propios, señala: "Quien frente a un negocio jurídico ineficaz lo cumple voluntariamente, no puede posteriormente pretender impugnarlo. Del mismo modo, quien ha aceptado dicho negocio jurídico ineficaz tampoco podrá más tarde desconocer la aceptación pretendiendo impugnar la validez del negocio."

Por tanto, mediante la doctrina jurídica de los Actos Propios, como acertadamente refiere Diez Picazo" "Se busca proteger la confianza que la propia conducta ha podido suscitar en los terceros, careciendo de viabilidad la alegación de cualquier posible error sufrido; sancionándose de este modo una contravención a la buena fe apreciada en sentido subjetivo, como intención leal, no habría mala fe cuando de lo que se trata es de rectificar las consecuencias de un error. La buena fe sería de este modo siempre una creencia o una ignorancia."

Además sostiene que el ir contra sus propios actos ha sido desde siempre proscrito en el derecho y que en el ordenamiento jurídico no se puede tolerar que un sujeto pretenda ejercitar un derecho en total contradicción con una conducta suya anterior que suscitaba confianza respecto al comportamiento que se iba a observar en esa relación jurídica.

En conclusión, podemos afirmar que quien expresa o tácitamente acepta la validez de un acto, por ejemplo, no cuestionándolo o no reclamando un supuesto incumplimiento, en su debida oportunidad, no puede pretender después impugnar su validez o reclamar un incumplimiento que nunca antes observó

\section{e) Efectos de la Aplicación de la Teoría}

Cuando se presenta el caso que alguna persona pretende desconocer, contradecir sus actos, su propia conducta anterior, el efecto reconocido en la Doctrina es que su indebida pretensión, la cual se encuentra en contradicción con sus propios actos anteriores, resultará desestimada por los tribunales de justicia, es decir, no podrá ser amparada legalmente.
Diez Picazo17 refiere: "Todo el camino que hemos recorrido hasta aquí nos ha servido para sentar esta conclusión: el acto de formular una pretensión contradictoria con el sentido objetivo que, según la buena fe, debía atribuirse a una conducta anterior del mismo sujeto, es un acto inadmisible...."

Morello $^{18}$, señala en esencia lo mismo: "La circunstancia de que un sujeto de derecho intente verse favorecido en un proceso judicial, asumiendo una conducta que contradice otra que la precede en el tiempo, en tanto constituye un proceder injusto, es inadmisible."

Agregando el citado autor ${ }^{19}$ "Si nadie puede ir válidamente contra sus propios actos y si la demanda que porta la pretensión muestra, sin embargo, que lo que en ella se afirma ha girado en redondo y en autocontradícción con lo que extraprocesalmente antes el ahora actor había conformado, es obvio que el legitimado pasivo tendrá la facultad de oponerse a través de la neutralización o bloqueo de la procedencia de esa demanda, mediante la deducción, en la contestación de una defensa sustancial más que procesal, destinada a que el juez en la decisión en el mérito, desestime el reclamo."

Consecuentemente, queda en evidencia que, de considerarse 
que existe una contradicción en la propia conducta, en los propios actos de una determinada persona, el efecto jurídico es que no van a ser amparables aquellas pretensiones planteadas que expresamente contradigan su propios actos realizados con anterioridad.

\section{f) La aplicación de la doctrina de los actos propios en el Perú}

Esta Doctrina es plenamente aplicable en el Perú. Se trata de una Doctrina que se deriva del principio general de la buena fe, recibido, aceptado y que inspira nuestro sistema jurídico.

Por tanto, su aplicación es una simple derivación del principio de la buena fe, el cual impone límites claros a la conducta de las personas, de las partes contratantes.

Por tanto, sin lugar a dudas podemos afirmar que el principio de que nadie puede contradecir sus propios actos es un principio general del derecho y en particular un principio que inspira el derecho peruano, motivo por el cual es plenamente aplicable de conformidad con lo preceptuado por el artículo VIII del Título Preliminar del Código Civil que textualmente establece: ".Los jueces no pueden dejar de administrar justicia por defecto o deficiencia de la ley. En tales casos, deben aplicar los principios generales del derecho $y$, preferentemente, los que inspiran el derecho peruano".
Al respecto, Borda $^{20}$ refiere: "La conducta contradictoria debe resultar inadmisible a la conciencia social por ser incompatible con la conducta primigenia. Por lo tanto, se está efectuando una valoración ética de la conducta que permite merituar la violación de la buena fe depositada por el sujeto receptor del acto. Esta inadmisibilidad de la conducta contradictoria deriva en su prohibición."

La aplicación de la doctrina de los Actos Propios en nuestra legislación, resulta sumamente clara por el hecho que el principio de la buena fe se encuentra recogido y contemplado, como señaláramos en el Art. VIII del Título Preliminar de nuestro Código Civil.

Veamos la siguiente Ejecutoria Suprema mediante la cual se puede observar no solamente la fuerza vinculatoria del contrato, tal como así lo dispone el artículo $1361^{21}$ del Código Civil sino también la Doctrina de los Actos Propios:

"Las expresiones conte-
nidas en dicho contrato
(arrendamiento), constitu-
yen manifestación de vo-
luntad vinculante que no
pueden ser desconocidas,
siendo de aplicación la
doctrina de los actos pro-
pios que impide ir contra
los efectos que la propia
conducta haya generado a
favor de la contraparte"
(Ejecutoria Suprema del 17
de agosto 1,995).

"Las expresiones contenidas en dicho contrato (arrendamiento), constituyen manifestación de vopueden ser desconocidas, pueden ser desconocidas, siendo de aplicación la doctrina de los actos propios que impide ir contra los efectos que la propia conducta haya generado a favor de la contraparte" de agosto 1,995).
Finalmente analicemos la siguiente Casación:

\section{"El coejecutado no pue- de beneficiarse de su pro- pio dolo para ampararse en la nulidad del título de ejecución".}

(Casación Nro. 2849-2001, del 26 de agosto de 2002)

En cuanto los fundamentos por los cuales se declaró procedente el Recurso de Casación estos fueron los siguientes:

"Se ha declarado procedente el recurso de casación interpuesto por la causal prevista en el inciso segundo del artículo 386 del Código Procesal Civil, sustentada en la inaplicación de los artículos 156, 168 y 231 del Código Civil. Alega que en estos preceptos legales se advierte la plena validez y eficacia del título de ejecución de su demanda, por lo que no tiene sustento la contradicción amparada en la causal de nulidad formal del título de ejecución; asimismo, agrega que se debió tener en cuenta el principio general del derecho que nadie puede ampararse o beneficiarse en su propio dolo; entonces, los ejecutados no pueden invocar su propio dolo para beneficiarse, ya que ambos se han beneficiado de los créditos otorgados por la accionante, como es el pagaré anexado en la demanda".

Concluye con el siguiente considerando:

Borda, op cit. Pag. 77.

21 Artículo 1361 del Código Civil: “Los Contratos son obligatorios en cuanto se hayan expresado en ellos. Se presume que la declaración expresada en el contrato responde a la voluntad común de las partes y quien niegue esa coincidencia debe probarla". 
"Que en lo referente a la inaplicación del artículo 168 del Código Civil, regulatorio de la interpretación literal y del principio de buena fe, es evidente que el coejecutado no puede beneficiarse de su propio dolo para ampararse con la nulidad del título de ejecución. La buena fe consiste en un modelo de conducta ético-jurídica que tiene un aspecto negativo o de veto, en cuanto rechaza una conducta deshonesta. Según la teoría de los actos pro- pios, nadie puede contradecir sus propios actos".

Finalmente, reiteramos lo expuesto en las líneas precedentes, es decir, que la doctrina de los Actos Propios "venire contra factum proprium nulli conceditur", deriva del principio general de la buena fe, recibido, aceptado y que inspira en particular el derecho peruano. Principio jurídico de que nadie puede contradecir sus propios actos, buscando fomentar que las personas sean coherentes en su actuar cotidiano, sancionando a aquellas que se comportan posteriormente en forma contradictoria quitándoles en consecuencia la posibilidad de reclamar derechos que en un primer momento sí hubieran podido reclamar.

En conclusión: La doctrina de los actos propios tiene por regla "que nadie puede ir contra sus propios actos" y como norma "un mandato de observar una conducta coherente". 